\title{
Silver Loading Effect for the Activated Carbon Fibers Pre-treated with Acid
}

\author{
Won-Chun $\mathrm{Oh}^{*}$ and Min-Hyung Yum ${ }^{\dagger}$ \\ Dept. of Adw. Mat. Sci. \& Eng., Hanseo Universitw, Chungnam 356-706, Korea \\ ${ }^{\dagger}$ Department of Applied Phvsics, Hanseo Lniversity, Chungnam 356-706, Korea \\ Received April 1, 200t
}

\begin{abstract}
The adsorption isotherms of $\mathrm{N}_{2}$ onto the metallic silver treated activated carbon fiber samples after acid treatment are Type I with a small amount of capillary condensation hyssteresis. Increasing amount of acid treatment leads to a decrease in $\mathrm{S}_{\mathrm{BET}} \mathrm{S}$ and external surface area. But. micropore volume and average pore diameter are presented in constant regular values with increasing amount of sulfuric acid treatment. SEM observes the surface morphology and cry'stal grown state of metal on the fiber surface. The results of EDX of $\mathrm{Ag}$-activated carbon fiber pre-treated with acid show the spectra corresponding to almost all samples rich in silver with increasing the amount of acid treated. The FT-IR spectra of Ag-activated carbon fiber show that the acid pre-treatment is consequently associated with the homogeneous dispersion of metal with the increased surface acidity of the activated carbon fiber. The type and quality of oxy gen groups are determined with Boelum titration method. From the those results. a positive influence of the acidic groups on the carbon fiber surface by acid treatment is also demonstrated by an increase in the contents of metallic silver with increasing of acidic groups.
\end{abstract}

Key Words : Adsorption isotherm. Silver-activated carbon fiber. SEM. EDX. Boehm titration

\section{Introduction}

Functional groups on the surface of microporous carbons are most likely subjected to a wide variety of inter- and intramolecular interactions. The relatively large numbers of oxy'gencontaining surface groups lead to oxidation of carbon surfaces containing a more hydrophilic surface structure. In general. the oxygen-containing surface groups behave as Bronsted acid-base characteristics. which may severely alter molecular interaction of parent carbon compounds. This can be used in the preparation of carbon supported metal catalysis by exchange with cationic metal complexes. Although carbon is considered to be an inert material in comparison with other catalyst supports. its surface is not as inert as expected because of the formation of active sites by the heteroatoms. In terms of carbon supported catalyst preparation, the presence of oxygen bearing is of great interest. In the related literatures. ${ }^{1,2}$ the influence of surface functional groups on the activity of carbon-supported catalysts has been clearly shown. Most of the chemical properties of activated carbon come from the incorporation of oxygen during its production, forming oxides like carboxylic, phenolic and lactonic groups. The modification of surface chemistry resulted in a significant change of the loading capacity and of the catalytic properties. ${ }^{3}$ These functional groups may play role in the sorption and deposition of nonpolar molecules and metallic ions by creating obstacles for physical adsorption and occurring the molecule from occupying the most energetically favorable position on the carbon surface. Metal treated activated carbon is a material having adsorption and catalysis; these

\footnotetext{
${ }^{*}$ Corresponding Author. Tel: -82-41-660-1337; Fax: -82-41-688-
} 3352: e-mail: wc_ohidzhanseo.ac.kr are of interest in several areas including medical applications. or water and air treatment for the catalytic removal of organic and inorganic pollutants and antibacterials. Especially. silver treated activated carbon by impregnation method is well known for its bacterial effects. ${ }^{4,5}$

In this paper. which is the first part of a study on the Agactivated carbon fiber system pretreated with various sulfuric acids. the purpose is to investigate the effects of physical and textural change of activated carbon fiber. and chenical treatment sequence. Full characterizations of silver loading effects for activated carbon fiber were presented by nitrogen adsorption properties. SEM-EDX analysis. FTIR results and properties of surface functional groups by Boelun titration.

\section{Experimental Section}

Preparation procedures. Self-made activated carbon fiber used as a non-treated carbon fiber material was prepared from PAN based carbon fiber. The carbonized PAN fiber was heated first at $823 \mathrm{~K}$ for burn off. and the carbon fibers were activated by steam diluted with nitrogen in a cylinder quartz glass tube in the temperature range of $1053-1073 \mathrm{~K}$ for $30 \mathrm{~min}$. These activated carbon fibers were washed with deionized water and dried for $24 \mathrm{~h}$ at ambient temperature. The molar concentration of from 0.01 to $0.1 \mathrm{M}$ diluted sulfuric acid at boiling temperature was used in the oxidation treatment to increase the formation of functional groups without the damage of the activated carbon fiber surface. The oxidation was carried out at the boiling temperature for $1 \mathrm{~h}$. The oxidized activated carbon fibers were washed and dried at $323 \mathrm{~K}$ for $24 \mathrm{~h}$. We prepared series of solutions, mole concentrations of 0.01 to 0.1 of $\mathrm{AgNO}_{3}$, 
for the metal loading effects. The doubly distilled water to dissolve the chemicals for the free from impurities was used. For the treatment, $2 \mathrm{~g}$ of chop typed ACFs were dipped in to $50 \mathrm{ml}$. of each silver ion dissolved aqueous solutions and stirred for 12 hours at room temperature. Then, we removed air and bubbles in the solutions under the pressure of about $1.33 \mathrm{~Pa}$ for 30 minutes, and then discarded the solution. Finally, these samples were dried at $368 \mathrm{~K}$ for 72 hours in air atmosphere. In order to reduce the experimental error, sample dryness was conformed through the whole experiments prior to use.

Measu rement. Nitrogen adsorption isotherms were obtained by using BГT surface area apparatus (ASAP 2010. Micrometrics) at $77 \mathrm{~K}$. Before the experiment the samples were heated at $473 \mathrm{~K}$ and then outgassed at this temperature under a vacuum of $1.33 \times 10^{-3} \mathrm{~Pa}$ to constant pressure. The isotherms were used to calculate the specific surface area and pore volume. The pore size distribution curves of micropores were obtained by the Hakins-Jura ( $\mathrm{H}-\mathrm{J}$ ) method. Scanning electron microscopy (SEM, ISM-5200 JОГJ., Japan) was used to observe the pore structure of silver treated activated carbon fiber and the treated silver particles state on the carbon fiber surfaces. For the elemental analysis of silver contents in activated carbon fibers treated with silver, FDX was also used. As one of the analysis of functional groups, FT-IR spectroscopy (FTS 3000MX. Biored $\mathrm{Co}$.) was used to characterize of silver loading effect of Ag-activated carbon fibers. The silver supported activated carbon fibers after sulfuric acid treatment were examined by $\mathrm{KBr}$ method using the spectroscopy. Discs for the method were prepared by tirst mixing $1 \mathrm{mg}$ of powdered Agactivated carbon fiber with $600 \mathrm{mg}$ of $\mathrm{KBr}$ (for FTIR spectroscopy) in an agitate mortar, and then pressing the resulting mixture successively under a pressure of $450 \mathrm{~kg} /$ $\mathrm{cm}^{2}$ for $3 \mathrm{~min}$. The spectra of the samples were measured between 4000 and $500 \mathrm{~cm}^{-1}$.

Boehm titration. We used to Boelum titration method ${ }^{6}$ for the identification of oxygenated surface group on the carbon fiber surfaces. One gram of Ag-activated carbon fiber sample was placed in $50 \mathrm{~mL}$ of the following $0.05 \mathrm{M}$ solutions: sodium hydroxide, sodium carbonate, sodium bicarbonate, and hydrochloric acid. The elenmeyer flasks were sealed and shaken for $24 \mathrm{~h}$ and then $5 \mathrm{~mL}$ of each filtrate was pipetted and excess of base and acid was titrated with $\mathrm{HCl}$ and $\mathrm{NaOH}$, respectively. The numbers of acidic sites of various types were calculated under the assumption that $\mathrm{NaOH}$ neutralizes carboxylic, phenolic, and lactonic groups; $\mathrm{Na}_{2} \mathrm{CO}_{3}$, carboxylic and lactonic groups; and $\mathrm{NaHCO}_{3}$, only carboylic groups. The number of surface basic sites was calculated from the amount of hydrochloric acid, which reacted with the carbon fiber.

\section{Results and Discussion}

The nitrogen adsorption isotherms at $77 \mathrm{~K}$ onto the silver supported activated carbon fiber samples after sulfuric acid treatments are shown in Figure 1. The $S_{B E 1 S}$ and porous structure of the Ag-activated carbon fibers are summarized in Table 1 . The isotherms presented in this Figure 1 show that the total sorption uptake decreases with increasing amount of acid treatment. All of the Ag-ACFs gave Type I isotherms characterized by plateau that is nearly horizontal to the $\mathrm{p} / \mathrm{p}_{\mathrm{o}}$ axis. This means that all the treated ACFs are microporous. It can be seen that both the external surface area and the total pore volume decreases as the distribution of silver on the activated carbon surfaces after acid treatments. Differences in the shape of these isotherms are not very significant, evidencing general similarities in the pore structure of the Ag-activated carbon fiber samples pretreated with sulfuric acid. Oh et al ${ }^{7.8}$ reported that the BГT surface area is considerably decreased due to the blocking of the narrow pores by surface complexes introduced by pre-

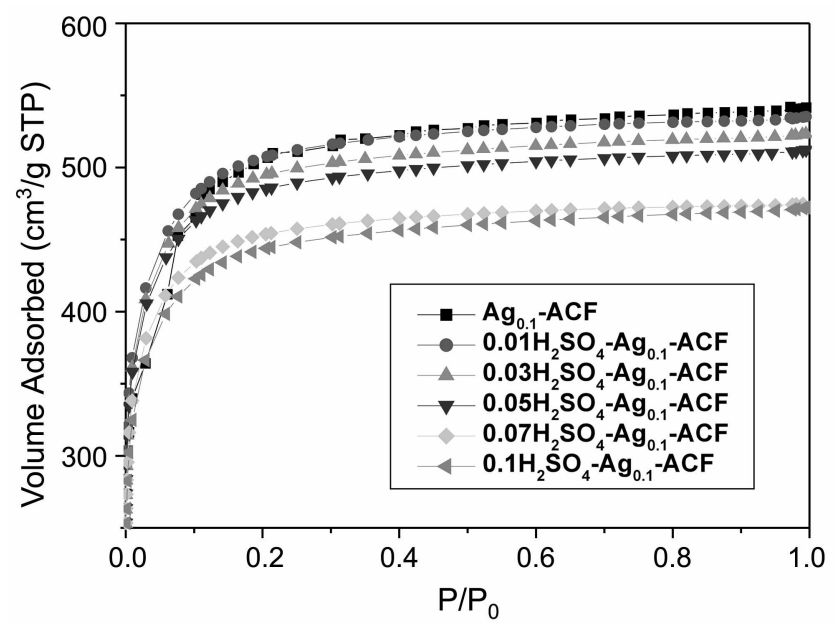

Figure 1. Adsorption isotherm of $\mathrm{V}_{2}$ at $77 \mathrm{~K}$ onto the acid pretreated activated carbon fibers loaded with silver.

Table 1. Comparison of physical parameters of metallic silver supported activated carbon fibers after sulfuric acid treatment

\begin{tabular}{|c|c|c|c|c|}
\hline \multirow{2}{*}{ Sample } & \multicolumn{4}{|c|}{ l'arameler } \\
\hline & $S_{\mathrm{BST}}\left(\mathrm{m}^{2} / \mathrm{g}\right)$ & Micropore Volume (ml $\mathrm{g}$ ) & l:xtemal Surface Nrea $\left(\mathrm{m}^{2} \mathrm{~g}\right)$ & Average Pore Diameter $(\lambda)$ \\
\hline$\Delta g_{0} 1-A C l:$ & 1923 & 0.554 & 527.7 & 17.39 \\
\hline $0.01 \mathrm{H}_{2} \mathrm{SO}-\mathrm{A}-\mathrm{Ag}: \mathrm{I}-\mathrm{ACF}$ & 1924 & 0.568 & 411.6 & 17.13 \\
\hline $0.03 \mathrm{I}_{2} \mathrm{SO} \mathrm{O}_{-}-\mathrm{Ag} \mathrm{g}_{1}-\mathrm{ACF}$ & 1881 & 0.574 & 475.9 & 17.17 \\
\hline $0.05 \mathrm{H}_{2} \mathrm{SO}-\mathrm{Ag}$ & 1845 & 0.570 & 442.3 & 17.17 \\
\hline $0.07 \mathrm{I}_{2} \mathrm{SO}_{-}-\mathrm{Ag} \mathrm{g}_{1} \mid \mathrm{I}-\mathrm{ACF}$ & 1730 & 0.544 & 355.8 & 16.95 \\
\hline $0.1 \mathrm{ll}_{2} \mathrm{SO}_{4}-\mathrm{Ag}_{0}-\mathrm{ACl}$ & 1686 & 0.511 & 396.9 & 17.27 \\
\hline
\end{tabular}


treated acids.

The pore size distributions (PSD) calculated for Ag-ACFs using the $\mathrm{H}-\mathrm{J}$ method $^{7}$ are shown in Figure 2. There is one major peak $0-20 \AA$, which is located in the micropore ranges. And another minor peak is located in ranging from 30 to $45 \AA$. The pore volume of micropores decreases with increasing amount of acid treatment. which is result of chemical and physical changes by sulfuric acid treatment of both internal and external surface in the Ag-activated carbon fibers. As shown in Table 1. $\mathrm{S}_{\mathrm{BLi} \text { IS }}$ were distributed between 1685 and $1923 \mathrm{~m}^{2} / \mathrm{g}$. In addition to, external surface areas were distributed between 355.8 and $527.7 \mathrm{~m}^{2} / \mathrm{g}$. Increasing amount of acid treatment leads to a decrease in $S_{\mathrm{B} \mathrm{L}^{\circ} \mid \mathrm{S}} \mathrm{s}$ and external surface area. But, micropore volume and average pore diameter are presented in constant regular values with increasing amount of sulfuric acid treatment. That is, the number of pores decreases with acid treatment, but the micropores of activated carbon fiber are not sufficiently created as acid pre-treatment effect with decreasing of $\mathrm{S}_{\mathrm{B} \text { Li }[\mathrm{S}} \mathrm{s}$.

The crystal-grown state and surface morphology of silver on the activated carbon fiber surface were observed by scanning electron microscopy. The fine particles and aggregated metallic Ag particles were observed on the surfaces of some carbon tibers as indicated in Figure 3. As shown in this Figure 3, the aggregated metallic Ag particles are presented in increase with increasing amount of sulfuric acid treatment. From these results, one can obviously observe the highly developed creaks and cavities, and heterogeneous distributed metallic Ag particles on the carbon fiber surface. Comparing acid free samples, samples treated with acid

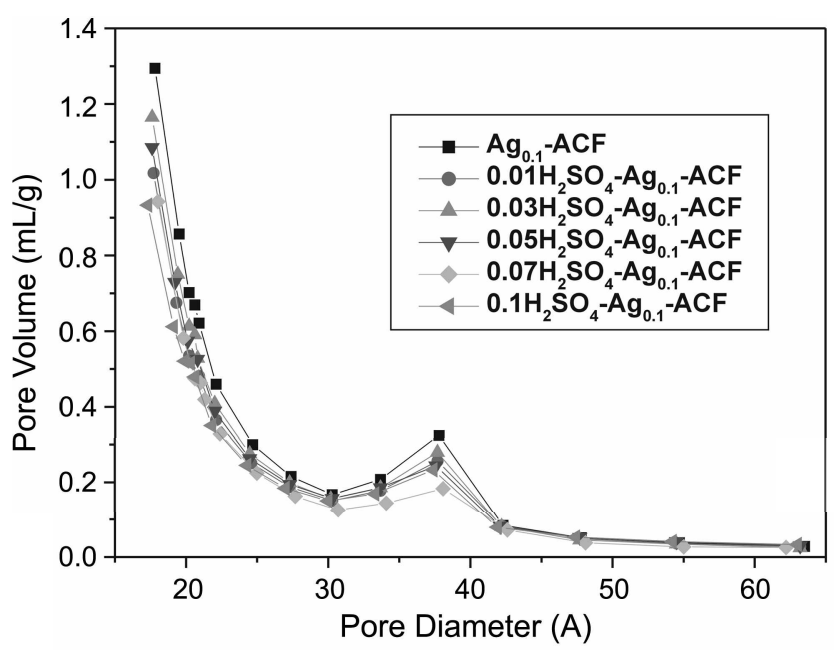

Figure 2. Pore size distributions of the acid pre-treated activaled carbon fibers loaded with silver.

were revealed to homogeneously distribution of fine silver particles. It can be considered that treated metallic silvers give considerable transformation to the outer surface states of activated carbon fiber treated with acid. And, it is shown that coalescing and particles blocked up some micropores on the surface increase with increasing the acid concentration treated. For the elemental analysis of metal supported activated carbons after acid treatment, samples were analyzed by Tnergy disperse X-ray (ГDX). Tnergy disperse $X$-ray (FDX) spectra of Ag-activated carbon fibers pretreated with sulfuric acid are shown in Figure 4. From the

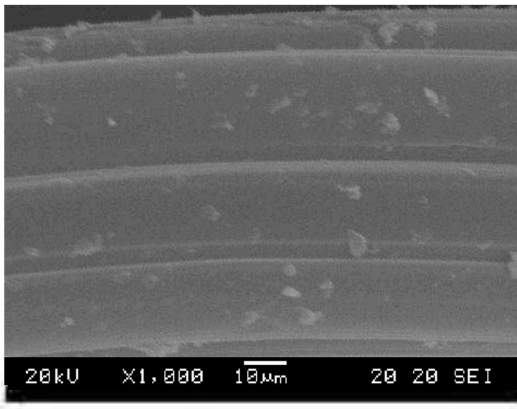

(a)

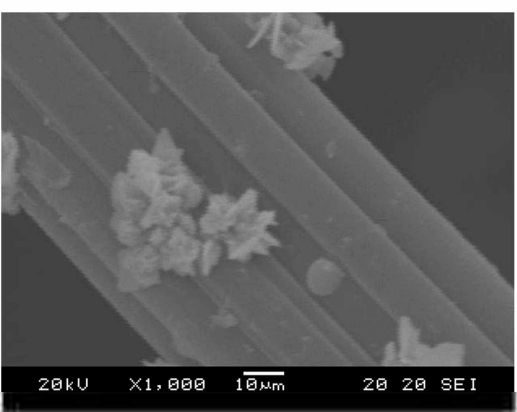

(d)

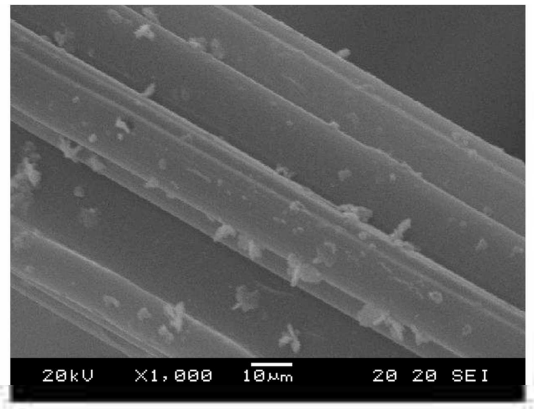

(b)

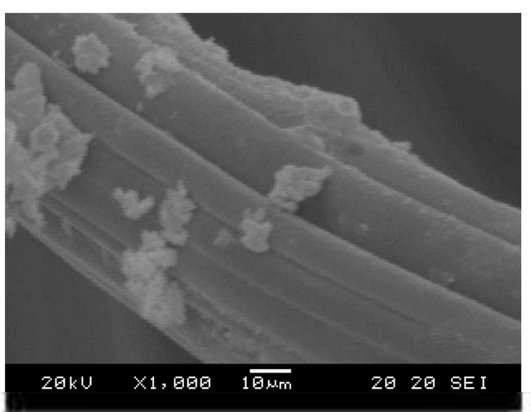

(e)

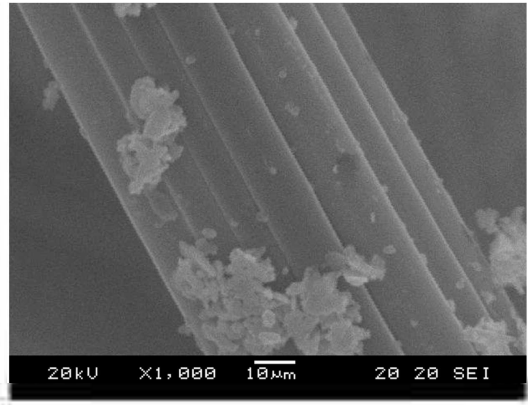

(c)

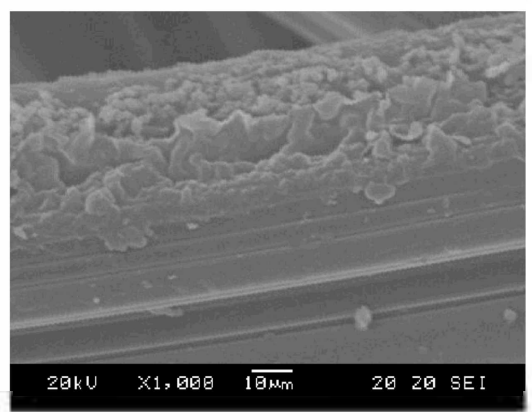

(f)

Figure 3. SEM micrographs of acid tree metallic silver supported activated carbon tiber and metallie silver supported activated carbon libers alter sulfuric acid trealments: (a) $\mathrm{Ag}_{0.1}-\mathrm{ACF}$. (b) $0.01 \mathrm{H}_{2} \mathrm{SO}_{4}-\mathrm{Ag} \mathrm{g}_{0.1}-\mathrm{ACF}$. (c) $0.03 \mathrm{H}_{2} \mathrm{SO}_{4}-\mathrm{Ag} \mathrm{g}_{0.1}-\mathrm{ACF}$. (d) $0.05 \mathrm{H}_{2} \mathrm{SO}_{4}-\mathrm{Agg}_{0.1}-\mathrm{ACF}$. (e) $0.07 \mathrm{H}_{2} \mathrm{SO}_{4}-\mathrm{Ag}_{0.1}-\Lambda \mathrm{Cl}^{2}$ and (1) $0.1 \mathrm{II}_{2} \mathrm{SO}_{4}-\Lambda \mathrm{g}_{0.1}-\mathrm{ACl}$. 
results, it shows the presence of $\mathrm{C}, \mathrm{Ag}$ and $\mathrm{O}$. In case of most of samples, carbon and silver are present as major elements in the activated carbon treated with metal. And, these results presented for each samples are shown the spectra corresponding to almost all samples rich in silver with increasing of the amount of acid treated. Note that a increasing of the amount of $\mathrm{Ag}$ contents $(52.31 \%)$ with increasing $\mathrm{O}$ contents $(7.32 \%)$ is observed for the $0.1 \mathrm{H}_{2} \mathrm{SO}_{4^{-}}$ $\mathrm{Ag}_{i, 1}$-ACF (Fig. 4(f)), which becomes more homogeneous as the carbon fiber surface is oxidized. The results of SFM and $\mathrm{CDX}$ indicate that the functional groups of activated carbons fiber surface by acid treatment are affects to the dispersion of the metallic silver. As already known from another study, the stability of the graphene layers (basal planes) is high. Therefore, oxygen surface groups are expected to be located at the edges of the basal planes, which are relatively weak sites of carbon structure and oxidation progresses slowly into the basal planes.

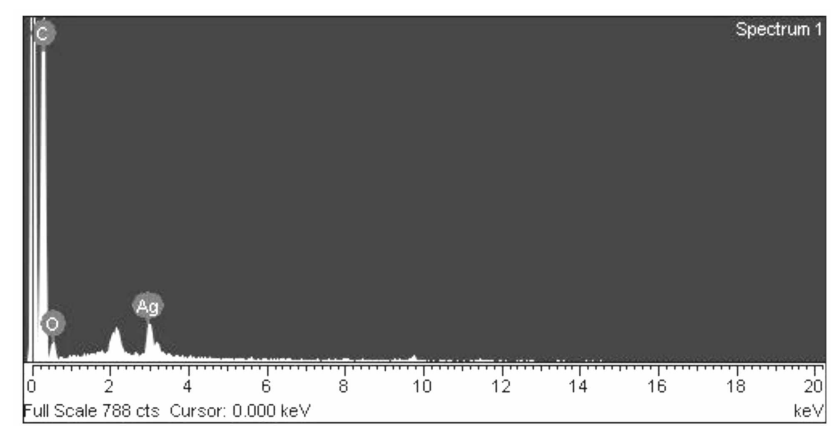

(a)

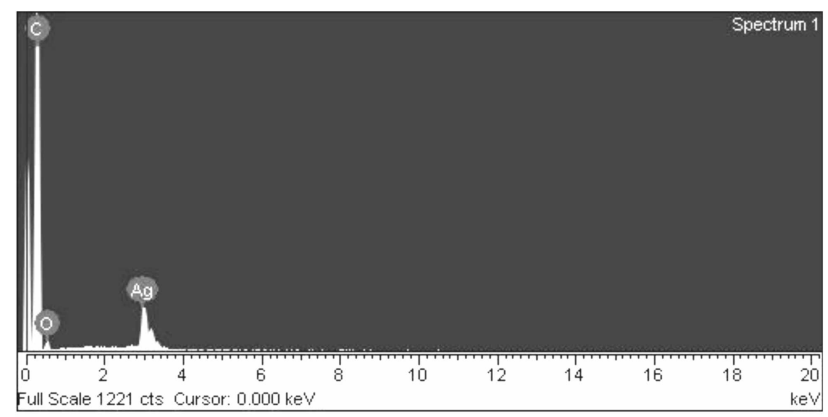

(c)

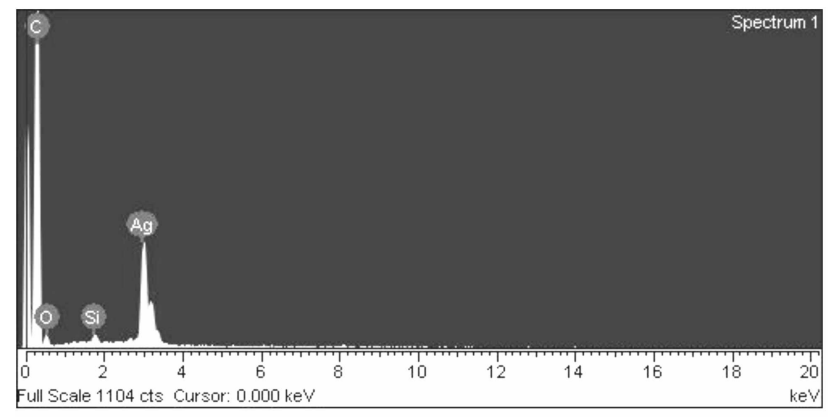

(e)
The FT-IR spectra of an Ag-activated carbon fiber pretreated with sulfuric acid treatment are shown in Figure 5. Observation of the absorption bands shows that the changes between the oxidized (acid treatment) and non-oxidized (non treatment) carbon fiber samples are mainly due to the formation functional groups. As shown in Figure 5, the intensity of spectra decreases with increasing amount of sulfuric acid treatment. The $v(\mathrm{C}-\mathrm{O})$ mode of the methoxy groups depends on the chemical structure of the adsorption sites. Absorption of $\mathrm{C}-\mathrm{O}$ followed by IR spectra has been used to characterize treated and non-treated metal catalysts. The frequency of $v(\mathrm{C}-\mathrm{O})$ of adsorbed carbon monoxide is often treated as an indicator characterizing the local coordination. This is also suitable for examining the state of metal ions situated differently on the solid surface. The most characteristics changes are observed at $1366 \mathrm{~cm}^{-1}$ of the presence of $\mathrm{C}-\mathrm{O}$ - containing structures $\left(v_{\mathrm{s}}\right.$ of $\left.\mathrm{COO}^{-}\right)$. The spectra show the presence of an absorption band at $1600 \mathrm{~cm}^{-1}$.

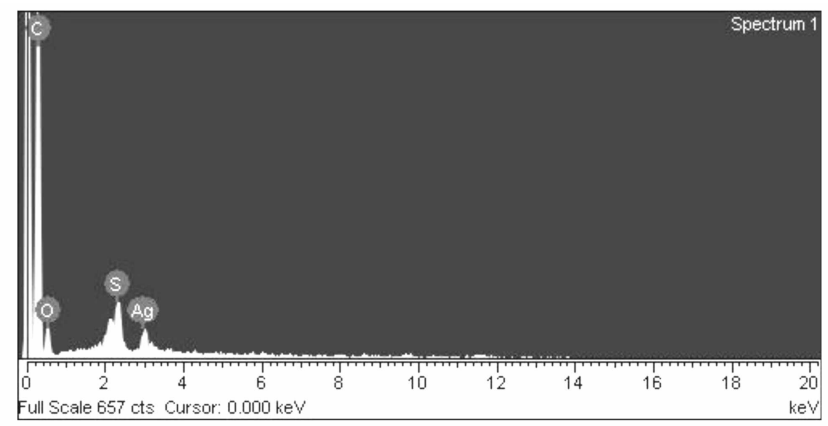

(b)

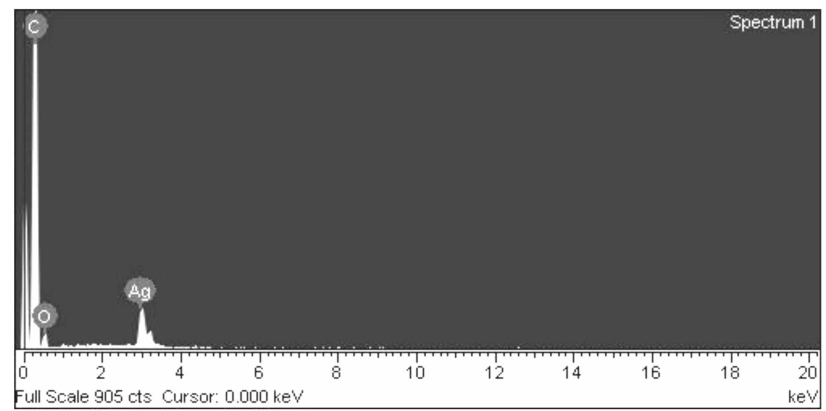

(d)

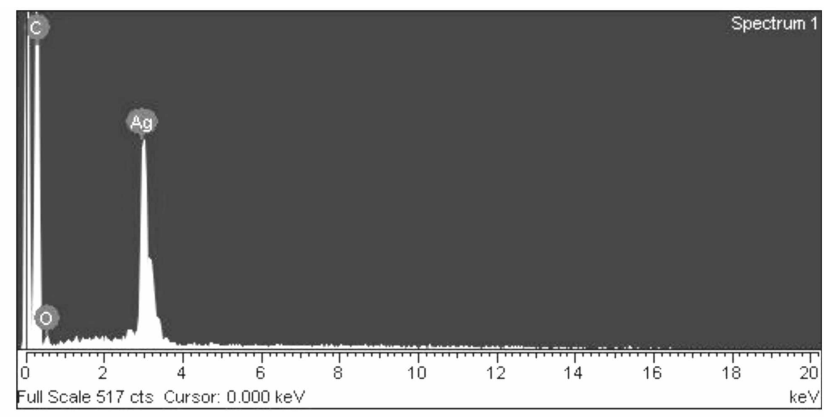

(f)

Figure 4. F.DX elemental micro-analysis of acid free metallic silver supported activated carbon fiber and metallic silver supported activated

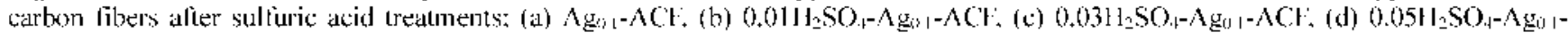
$\Lambda C l:$ (c) $0.07 \mathrm{I}_{2} \mathrm{SO}_{4}-\Lambda \mathrm{g}_{1,1}-\Lambda \mathrm{Cl}$ and (t) $0.11 \mathrm{I}_{2} \mathrm{SO}_{4}-\Lambda \mathrm{g}_{2,1}-\Lambda \mathrm{Cl}$. 
Table 2. Number of Surface Species (med/g) Obtained from Bochm Tïtration

\begin{tabular}{|c|c|c|c|c|c|}
\hline \multirow{2}{*}{ Sample } & \multicolumn{5}{|c|}{ Functional (iroup (meg/g) } \\
\hline & Carboxylic & I.actonic & Phenolic & Acidic & Basic \\
\hline$\Lambda g_{0}-\Lambda C F$ & 1.01 & 0.52 & 0.90 & 2.43 & 1.31 \\
\hline $0.01 \mathrm{H}_{2} \mathrm{SO}_{1}-\lambda \mathrm{g}_{1,1,1}-\mathrm{ACF}$ & 1.56 & 0.73 & 0.95 & 3.24 & 1.12 \\
\hline $0.03 \mathrm{H}_{2} \mathrm{SO}_{-}-\lambda \mathrm{g}_{1,1,1}-\Lambda \mathrm{CF}$ & 1.66 & 1.32 & 2.87 & 5.85 & 1.22 \\
\hline $0.05 \mathrm{H}_{2} \mathrm{SO}_{-}-\mathrm{Ag}_{1,1,1}-\mathrm{ACF}$ & 2.03 & 1.85 & 2.33 & 6.21 & 1.11 \\
\hline $0.07 \mathrm{H}_{2} \mathrm{SO}_{-1}-\mathrm{Ag}_{1,1}-\mathrm{ACF}$ & 1.95 & 2.01 & 3.88 & 7.84 & 1.13 \\
\hline $0.1 \mathrm{H}_{2} \mathrm{SO}_{1}-\Lambda \mathrm{g}_{0,1}-\Lambda \mathrm{CF}$ & 4.56 & 3.21 & 3.09 & 10.86 & 1.45 \\
\hline
\end{tabular}

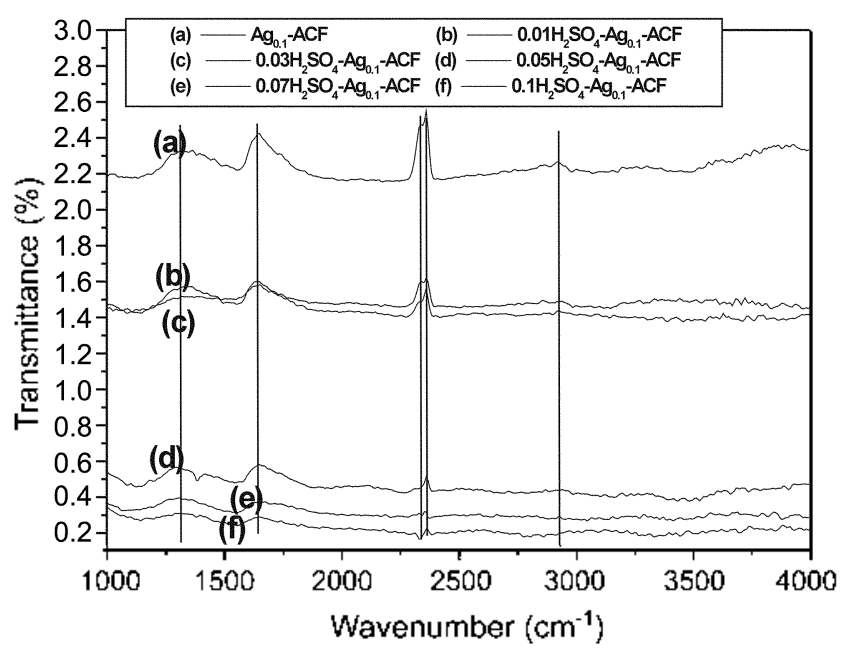

Figure 5. Inliared spectra recorded from the acid pre-treated activated carbon fibers loaded with silver; (a) $\Lambda \mathrm{g}_{0.1}-\Lambda \mathrm{Cl}$ ( (b) $0.01 \mathrm{H}_{2} \mathrm{SO}_{4}-\mathrm{Ag}_{0}-\mathrm{ACF}$. (c) $0.03 \mathrm{H}_{2} \mathrm{SO}_{4}-\mathrm{A} \mathrm{g}_{0 . \mathrm{l}}-\mathrm{ACF}$. (d) $0.05 \mathrm{H}_{2} \mathrm{SO}_{+}$ $\mathrm{Ag}_{0}-\mathrm{ACF}$ ( (e) $0.07 \mathrm{H}_{2} \mathrm{SO}_{4}-\mathrm{Ag}_{0}-\mathrm{ACF}$ and (1) $0.1 \mathrm{H}_{2} \mathrm{SO}_{4}-\mathrm{Ag}_{0}$ - $\mathrm{ACF}$.

These bands are due to $\mathrm{C}=\mathrm{C}$ stretching modes that weakly active in the IR because of breakdown of selection rules. The weak band appearing at $1366 \mathrm{~cm}^{-1}$ is ascribed to the formation of oxygen function groups like a highly conjugated $\mathrm{C}=\mathrm{O}$ stretching in carboxylic groups, and carboxylate moieties..$^{7}$ These results indicate that acid treatment gave rise to a greater increase in $\mathrm{C}=\mathrm{O}$ bonds in carboxylic acid and lactone groups. The acid treatment is consequently associated with the homogeneous distribution of silver with the increased surface acidity of the activated carbon fibers. The band observed at $2360 \mathrm{~cm}^{-1}$ is usually ascribed to the presence of aliphatic compounds. A broad band in the $3100-3500 \mathrm{~cm}^{-1}$ region, typically attributed to $\mathrm{O}-\mathrm{H}$ stretches from hydroxyl, phenolic and carboxylic groups are absent. Thus FIIR spectra confirm the formation of carbonyl groups during the oxidation process of acid treatment. The main goal of oxidation is to obtain a more hydrophilic surface with a relatively large number of oxygen containing oxygen groups on the fiber surfaces.

The FI'-JR spectra transformation described above are due to an alternation of the carbon surface via introduction of oxygen groups and removal some carbon atoms from matrix by acid treatment. The type and quality of oxygen groups are determined with Boehm titration method. 'The results obtained from the method proposed by Boehm are listed in Table 2. It can be observed that the total acidity and the distributions of groups of various strengths have very different values. The effect of surface acidity and basity was also evaluated from correlations as a function of $\mathrm{NaOH}, \mathrm{NaHCO}_{3}$ and $\mathrm{Na}_{2} \mathrm{CO}_{3}$ uptake. The surface acidity increases with increasing of the amount of acid treated. It is presented that $0.1 \mathrm{H}_{2} \mathrm{SO}_{4}-\mathrm{Ag}_{0.1}-$ ACF has the highest number of oxidation groups such as carboxylic, lactonic and phenolic groups. This may contribute to the lowest local $\mathrm{pH}$ of this carbon surface due to acid treatment. A positive influence of the acidic groups on the carbon fiber surface by acid treatment is also demonstrated by an increase in the contents of metallic silver with increasing of acidic groups calculated from Boehm titration. It is believe that the affinity of activated carbon fiber for silver depends on the amount of surface functional groups. When distribution of acidic groups is properly introduced, active sites on the carbon fiber surface should be play important role in the deposition of metallic ions. As expected. acid oxidation introduces a significant number of oxygen containing groups in almost each category classified by Boehm.

\section{Conclusion}

The adsorption isotherms of Ag-ACFs pre-treated with sulfuric acid are lype l. From the pore size distributions (PSD) calculated for our materials using the H-J method, these also confirm our hypothesis about the source of the microporosity being the metallic silver on the activated carbon fiber surfaces after various acid treatments. In case of SEM results, one can obviously observe the highly developed surface structures, and homogeneous distributed metals and grown crystal particles on the carbon fiber surface. The results of typical EDX elemental microanalysis of Agactivated carbon fibers pre-treated sulfuric acid show the spectra corresponding to almost all samples rich in silver with increasing the amount of acid treated. The Fl'-IR spectra of Ag-activated carbon fiber samples show that the acid treatment is consequently associated with the homogeneous distribution of metal with the increased surface acidity of the activated carbon fibers. The effect of surface acidity and basity was also evaluated from correlations as a function of $\mathrm{NaOH}, \mathrm{NaHCO}_{3}$ and $\mathrm{Na}_{2} \mathrm{CO}_{3}$ uptake. A effects of the acidic groups introduced on the carbon fiber surface by acid treatment is also demonstrated by an increase in the 
contents of metallic silver with increasing of acidic groups calculated from Boelm titration.

\section{References}

1. Rodríguez-Reinoso. F. Carbon $1998,36.159$

2. Román-Martinez. M. C.: Cazorla-Amorós. D.: Linares-Solano. A.: Salinas-Martinez de Lecea. C. Carton 1993, 31. 895.

3. Vinke. P.: van der Eijk. M.: Verbree. M.: Voskamp. A. F.: van Bekitum, H. Carbon 1994, 32.675.
4. Oh. W. C. . Ind Eng. Chem $2003,9,117$

5. Kimn. J. K.: Oh. W. C.: Kimn. M. K. J. of Korean Ind \& Eng. Chent 1998. 9.729

6. Boehm. H. P. Adances in Catahsis: Academic press: New York. 1966: Vol 16. p 172.

7. Oh. W. C.; Yum, M. H; Lee. Y. S. $30^{\text {di }}$ Ammal MeetingProceeding of Carbon Haterial Confenence, Carbon Society of Japan1: 2003: p 204

8. Oh. W. C. Bull. Korean Chen. Soc. 2004. $25(5) .639$.

9. Donnet. J. B.: Bansal. R. C. Carbon Fibers: Marcel Dekker: New York. 1990: Vol. 3, Chap. 3. 